\title{
Comparison of Classic and Metal Reinforced Maxillary Acrylic Complete Dentures Fracture Resistance
}

\author{
OANA CELLA ANDREI ${ }^{1 *}$, RUXANDRA MARGARIT ${ }^{2 *}$, MIHAI BURLIBASA ${ }^{3}$, ADRIANA BISOC ${ }^{1}$, ADINA MAGDALENA BUNGET ${ }^{4}$, \\ CATALINA FARCASIU ${ }^{5}$, MAGDALENA NATALIA DINA ${ }^{3}$, LIVIA ALICE TANASESCU ${ }^{1}$ \\ ${ }^{1}$ Carol Davila University of Medicine and Pharmacy, Faculty of Dentistry, Department of Removable Prosthodontics, 37 Dionisie Lupu Str., 020021, \\ Bucharest, Romania \\ ${ }^{2}$ Carol Davila University of Medicine and Pharmacy, Faculty of Dentistry, Department of Restorative Odontotherapy, 37 Dionisie Lupu Str., 020021, \\ Bucharest, Romania \\ ${ }^{3}$ Carol Davila University of Medicine and Pharmacy, Faculty of Midwifery and Nursing, Department of Dental Techniques, 37 Dionisie Lupu Str., \\ 020021, Bucharest, Romania \\ ${ }^{4}$ University of Medicine and Pharmacy, Faculty of Dentistry, Department of Prevention of Oro-Dental Diseases, 2 Petru Rares Str., 200349, Craiova, \\ Romania \\ ${ }^{5}$ Carol Davila University of Medicine and Pharmacy, Faculty of Dentistry, Department of Pedodontics, 37 Dionisie Lupu Str., 020021, Bucharest, \\ Romania
}

The aim of our study was to evaluate fracture resistance of the PMMA complete dentures and to make a comparison between the classic acrylic maxillary complete dentures and the metal-reinforced ones, in terms of fracture resistance during function and to compare the fracture pattern of the two groups of complete dentures. We used maxillary complete dentures made of heat-processed acrylate, 5 exclusively and 5 in which a metal-cast net in the form of a mesh was inserted after being casted, worn by patients for a period of 5 years. A bilateral progressive force was applied to the PM2-M1 area until the samples failed, recording the force value at which the first change occurred. A Universal Loading Machine was used. The results were analyzed using the ANOVA method. For the classic acrylic complete dentures group, the minimum fracture force value was $1060 \mathrm{~N}$, the maximum fracture force value being $2443 \mathrm{~N}$. For the reinforced complete dentures group, the minimum fracture force value was $3320 \mathrm{~N}$, the maximum value being $3760 \mathrm{~N}$. Statistical analysis of data using the ANOVA shows that the results are statistically relevant, with a p value of $0.000137(p<0,05)$. All the dentures from the classic acrylic complete dentures group fractured presenting two or more fracture lines, most of them involving also fractures on the acrylic teeth and breaking into multiple pieces, while all the dentures from the reinforced complete dentures group fractured presenting one or two fracture lines, most of them without detachable fragments and involving also fractures on the acrylic teeth.

Keywords: complete dentures, fracture resistance

Despite the advances in dental medicine and the widespread use of dental implants, the prosthetic rehabilitation of the complete edentulous patients frequently implies conventional acrylic dentures [1]. In order to satisfy the requirements of such prosthetic treatment, the materials from which the dentures are made must be biocompatible, inexpensive, aesthetic, easy to repair and sanitized and resistant to the action of the forces exerted during function [2,3]. Polymethyl methacrylate is the most commonly used material for manufacturing of denture bases and artificial teeth [4]. There are several types of acrylic resins with different processing methods, one of which is to use the thermal energy that activates benzoyl peroxide in the resin composition, initiating the polymerization process. Denture's fracture is one of the most frequent accident. Studies conducted on its causes and incidence show that maxillary dentures are more exposed to fracture compared to mandibular ones, as a result of impact forces or flexural fatigue [5-8]. Because the fracture strength of PMMA is not always satisfactory, practitioners attempted to improve the physical qualities of this material by incorporating different types of fibers such as nylon, polyethylene, polyamide, glass fiber, ceramic fiber, or by reinforcing the acrylic base, inserting cast or bent solid metal nets as strengtheners, trying to increase flexural and impact strength as well as the fatigue resistance of the resin [9-12]. The aim of our study was to evaluate fracture resistance of the PMMA complete dentures and to make a comparison between the classic acrylic maxillary complete dentures and the metal-reinforced ones, in terms of fracture resistance during function and to compare the fracture pattern of the two groups of complete dentures.

*email: cella.andrei@gmail.com; ruxandra.margarit@gmail.com,Phone: 0040747440013

All authors have equally contributed to this paper. 


\section{Experimental part}

The study was carried out on a number of 10 upper complete acrylic dentures, with bases and artificial teeth made of thermoplastic PMMA, of which 5 had bases made exclusively of heat-processed acrylate and 5 were made of heat-processed acrylate in which a metal-cast net in the form of a mesh was inserted after being casted; all the artificial teeth used were acrylic prefabricated units. To ensure similarity to oral conditions, we used two methods; first, simulating mucosal resilience with a putty condensation silicone that exhibits elasticity after setting, and using complete dentures worn by patients for a period of 5 years. Samples were subjected to a bilateral progressive force applied to the PM2-M1 area. The flexural load was applied until the samples failed, recording the force value at which the first change occurred. A Universal Loading Machine (Lloyd Instruments) was used, with a maximum force of $5 \mathrm{kN}$ and a crosshead speed of $1.0 \mathrm{~mm} / \mathrm{min}$ (Figure 1). NEXYGEN Data Analysis Software was used to record the results. A representative fractured specimen is shown in Figure 2. The graphics show the dependency between load and extension for each sample, recording the force value at which the fracture occurred. At the same time, the area of minimal denture resistance was highlighted for each sample. The results were statistically analyzed using the ANOVA method.

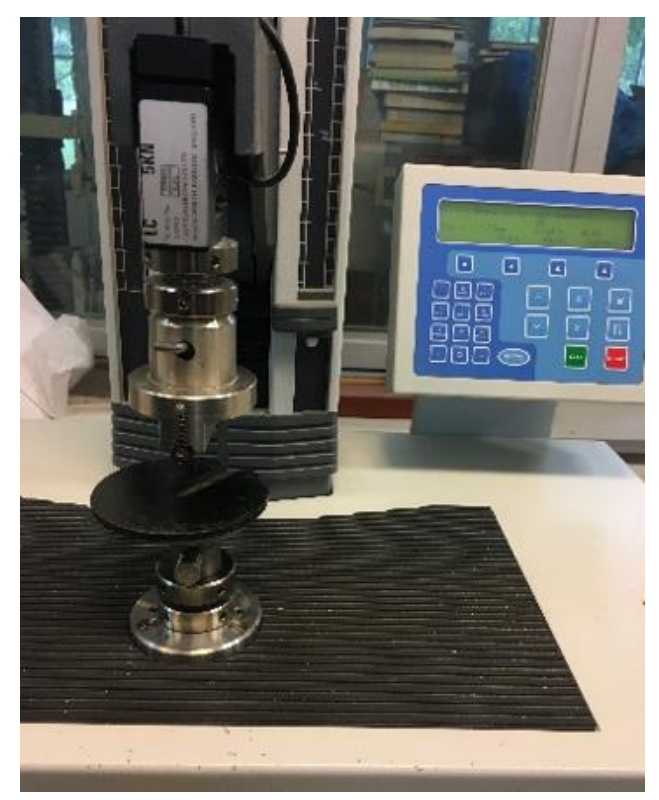

Fig. 1. The universal Loading Machine (Lloyd Instruments)

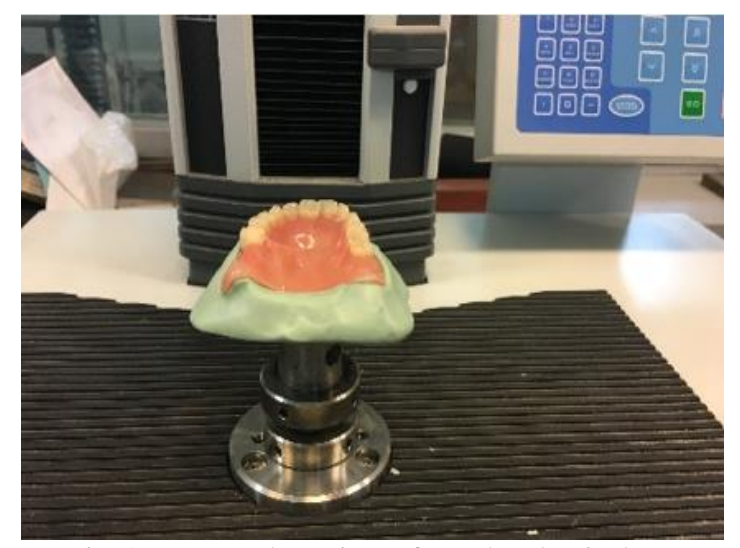

Fig. 2. Fractured specimen from the classical acrylic complete dentures group 


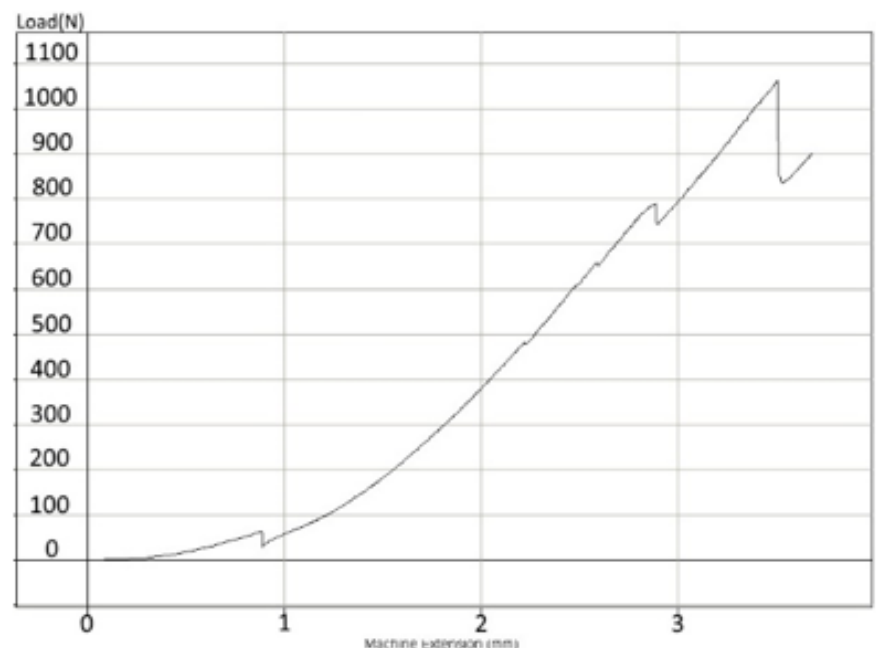

Fig. 3. The minimum fracture force value for the classic acrylic complete dentures group

\section{Results and discussions}

For the classic acrylic complete dentures group, the minimum fracture force value was $1060 \mathrm{~N}$, the maximum fracture force value being $2443 \mathrm{~N}$, with an average of $1722.4 \mathrm{~N}$ plus/minus 572,98 N (the standard deviation). Fracture force values for the classic complete dentures is shown in Table 1. The graph with the minimum fracture force values is shown in Figure 3 and the maximum in Figure 4.

Table 1

FRACTURE FORCE VALUES FOR THE CLASSIC COMPLETE DENTURES

\begin{tabular}{|c|c|c|c|c|}
\hline 1 & 2 & 3 & 4 & 5 \\
\hline $1060 \mathrm{~N}$ & $1235 \mathrm{~N}$ & $1824 \mathrm{~N}$ & $2050 \mathrm{~N}$ & $2443 \mathrm{~N}$ \\
\hline
\end{tabular}

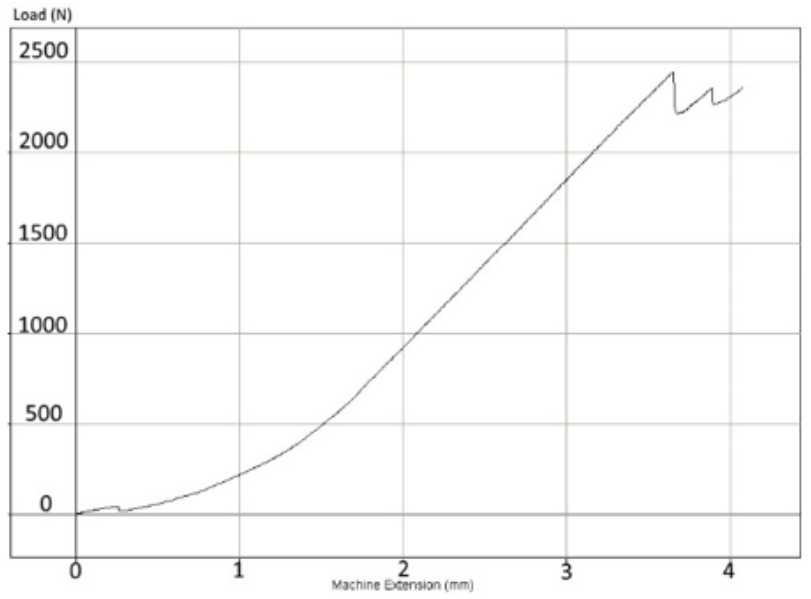

Fig. 4. The maximum fracture force value for the classic acrylic complete dentures group

Table 2

FRACTURE FORCE VALUES FOR THE REINFORCED COMPLETE DENTURES

\begin{tabular}{|c|c|c|c|c|}
\hline 1 & 2 & 3 & 4 & 5 \\
\hline $3320 \mathrm{~N}$ & $3405 \mathrm{~N}$ & $3620 \mathrm{~N}$ & $3690 \mathrm{~N}$ & $3760 \mathrm{~N}$ \\
\hline
\end{tabular}




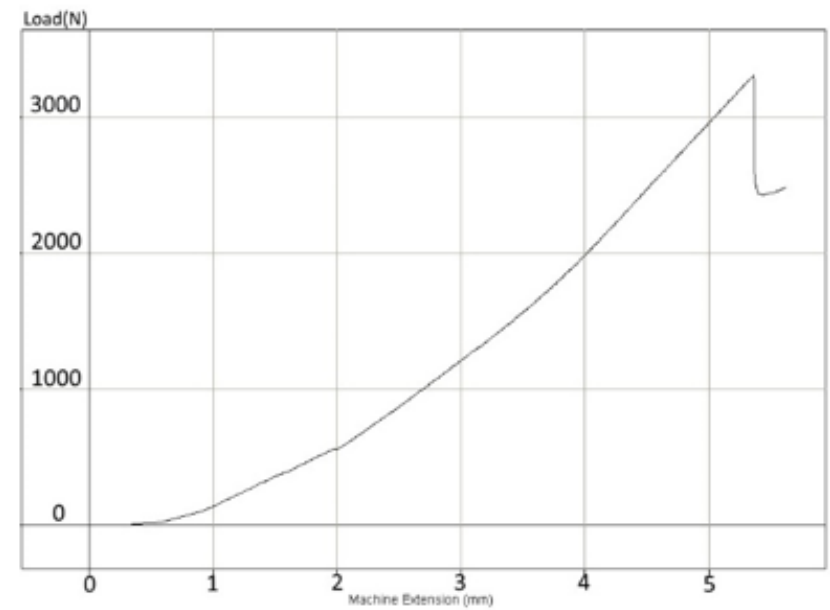

Fig. 5. The minimum fracture force value for the reinforced complete dentures group

For the reinforced complete dentures group, the minimum fracture force value was $3320 \mathrm{~N}$, the maximum value being $3760 \mathrm{~N}$, with an average of $3559 \mathrm{~N}$ plus/minus 188,49 N (the standard deviation). Fracture force values for the reinforced complete dentures are shown in Table 2. The graph with the minimum fracture force value is shown in Figure 5 and the maximum in Figure 6.

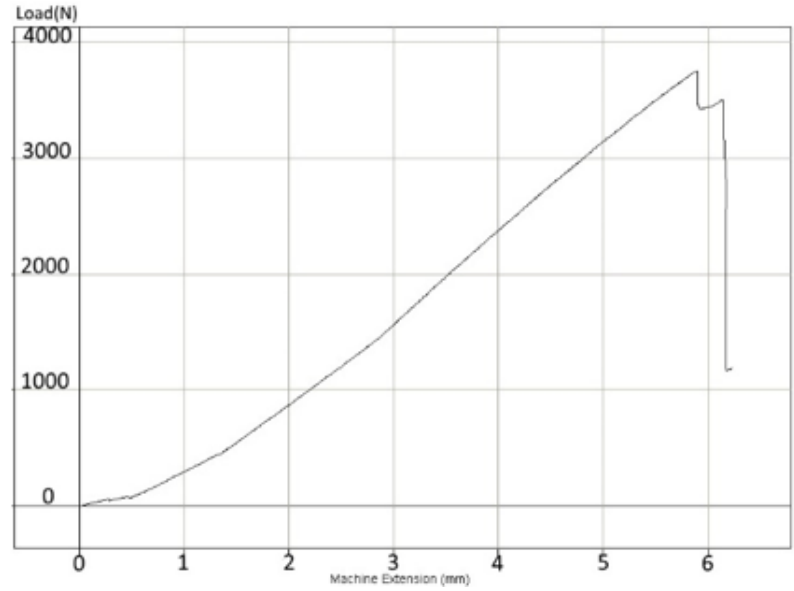

Fig. 6. The maximum fracture force value for the reinforced complete dentures group

Table 3

COMPARISON BETWEEN THE FRACTURE RESISTANCE OF THE TWO TYPES OF ACRYLIC COMPLETE DENTURES

\begin{tabular}{|c|c|c|}
\hline & Classic complete dentures & Reinforced complete dentures \\
\hline standard deviation & 572.9836821 & 188.4940317 \\
\hline mean & 1722.4 & 3559 \\
\hline median & 1824 & 3620 \\
\hline
\end{tabular}

Table 4

ANOVA METHOD AND $\mathrm{p}$ VALUE

\begin{tabular}{|l|l|l|l|l|l|l|}
\hline & ANOVA & & & & \\
\hline & Source of Variation & SS & af & MS & F & P-value \\
\hline & Between Groups & 8432748.9 & 1 & 8432749 & 46.35412 & 0.000137 \\
\hline & Within Groups & 1455361.2 & 8 & 181920.2 & 5.317655 \\
\hline & & & & & & \\
\hline & & & & & & \\
\hline & Total & 9888110.1 & 9 & & & \\
\hline
\end{tabular}

The comparison between the fracture resistance of the two types of acrylic complete dentures is shown in Table 3 . 
Statistical analysis of data using the ANOVA method shows that the results are statistically relevant, with a $\mathrm{p}$ value of $0.000137(\mathrm{p}<0,05)$ (Table 4.), in regards to the differences between fracture resistance among the two types of acrylic complete dentures.

The dentures from the classic maxillary complete dentures group proved to be more susceptible to fracturing into multiple pieces, involving both the base and the acrylic teeth in most cases, as shown in Figure 7 and Table 5, while those pertaining to the reinforced maxillary complete dentures group were more resistant to fractures, as shown in Figure 8 and Table 6.

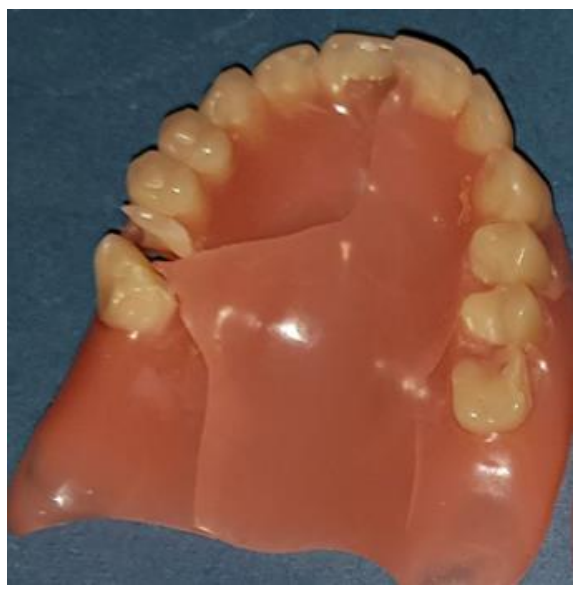

Fig. 7. Classic acrylic maxillary denture fractured into multiple pieces

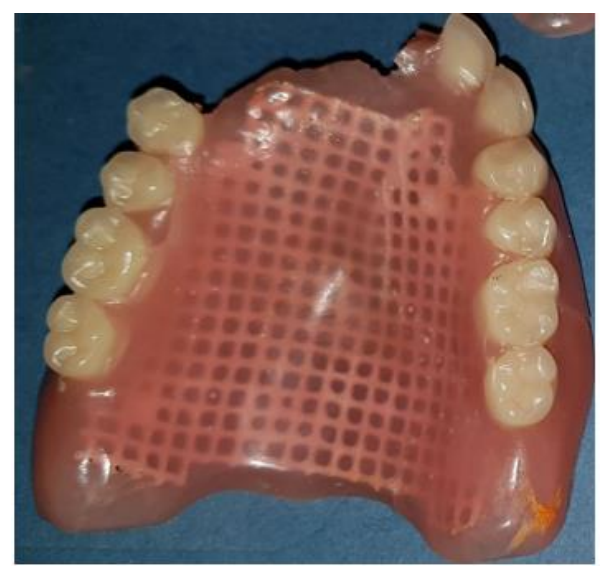

Fig. 8. Metal reinforced acrylic maxillary denture fractured mostly peripheral, outside the metal mesh zone

Table 5

THE FRACTURES IN THE CLASSIC COMPLETE DENTURES GROUP

\begin{tabular}{|l|l|l|l|l|l|}
\hline Classic complete dentures group & $\mathbf{1}$ & $\mathbf{2}$ & $\mathbf{3}$ & $\mathbf{4}$ & $\mathbf{5}$ \\
\hline Number of fracture lines & $\mathbf{3}$ & $\mathbf{2}$ & $\mathbf{4}$ & $\mathbf{3}$ & $\mathbf{3}$ \\
\hline Number of fragments & $\mathbf{4}$ & $\mathbf{3}$ & $\mathbf{5}$ & $\mathbf{4}$ & $\mathbf{4}$ \\
\hline Fracture of acrylic teeth & yes & no & yes & yes & no \\
\hline
\end{tabular}

Table 6

THE FRACTURES IN THE REINFORCED COMPLETE DENTURES GROUP

\begin{tabular}{|l|l|l|l|l|l|}
\hline $\begin{array}{l}\text { Reinforced complete dentures } \\
\text { group }\end{array}$ & $\mathbf{l}$ & $\mathbf{2}$ & $\mathbf{3}$ & $\mathbf{4}$ & $\mathbf{5}$ \\
\hline $\begin{array}{l}\text { Number of fracture lines in } \\
\text { denture base }\end{array}$ & $\mathbf{l}$ & $\mathbf{l}$ & $\mathbf{2}$ & $\mathbf{l}$ & $\mathbf{2}$ \\
\hline Number of fragments & 0 & 0 & $\mathbf{l}$ & 0 & $\mathbf{l}$ \\
\hline Fracture of acrylic teeth & yes & yes & no & yes & yes \\
\hline
\end{tabular}


All the dentures from the classic acrylic complete dentures group fractured along two or more fracture lines, most of them involving also fractures on the acrylic teeth and breaking into multiple pieces, while all the dentures from the reinforced complete dentures group fractured on one or two fracture lines, most of them without detachable fragments and involving also fractures on the acrylic teeth. For both groups, at least one fracture line was paramedian.

Fracture of acrylic complete dentures is one of the most frequent accidents faced by complete edentulous patients. Most bases of the complete dentures are made from acrylic resins which are not very strong and present brittle failure, cracking immediately without much bending; they have relatively low impact resistance and strength. The acrylic resin can be heatprocessed, self-polymerizable or, more recently, we can obtain a CAD/CAM resin denture base. By comparing the fracture resistance of the three types of resins, a study conducted in 2018 by Steinmass et al. concludes that, even if it is the most modern choice, the CAD/CAM denture base resin does not provide higher fracture resistance for the complete dentures compared to the other types of acrylic resins, and the heat-processed ones are superior in this respect to the selfpolymerizable [13]. Based on his results, we chose for our study only maxillary complete dentures with bases made of heatprocessed acrylate.

On the other hand, a study conducted by Bhattacharya et al., in 2014 shows that out of 649 complete dentures made of heat-processed acrylate and applied over a period of 18 months, 81 (12.33\%) were fractured [14]. This rather high percentage raises the problem of heat-PMMA resistance, used in fabrication of these complete dentures. The durability of complete dentures made from heat-processed acrylate was the subject of a study conducted in 2010 by Borţun et al. The results showed that this material guarantees a 5-year durability of total dentures [15]. Starting from this result, in our study we tested the fracture resistance of the complete maxillary dentures made from heat-processed acrylic resin that were worn by patients for a period of five years.

One of the factors that influences complete denture's fracture is the masticatory force. The masticatory force's value is extremely variable, studies showing intervals between 780 and $1180 \mathrm{~N}$ in complete dentulous healthy individuals [16]. The maximum masticatory force's value recorded in complete edentulous patients wearing dentures has a significantly lower value than that seen in dentulous patients. At the same time, studies show that the maximum force value in these patients varies according to the moment of recording relative to the moment of complete denture's application. Thus, even if this force has low initial value, some studies show a considerable increase after a period of 6 months [17], while other after a period of 7 weeks [18] from the application of the complete denture, as a result of patients' adaptation to the prostheses [18]. However, the value of the masticatory force remains lower than in dental subjects, by $20 \%-40 \%$ [17]. Okamoto, in 2012 , finds an average value of $412.61 \mathrm{~N}$ in complete denture patients [16]. Studies show that, from the point of view of localization, maximal masticatory force is developed in the first molar area [17-18], and it is also considered that $80 \%$ of the total masticatory force is distributed here. Taking into account the results of these researches, in our study the forces were applied in the first molar area, one of the purposes being to determine if the acrylic resin from which the complete denture is made can resist to the usual maximum forces exerted during mastication.

Inappropriate adaptation of the complete denture to the support tissues and its consecutive instability is the most common cause of fracture, studies showing that over $40 \%$ of the total denture fractures are determined by it; other causes are: incorrect occlusal relationships, accidentally droppings and polymerization defects resulting in porosities [19-21], the masticatory force being on the last place [19]. In 2017, Shakir et al., conducted a study on 160 patients and found that lack of adaptation of the denture to the support tissues is the second cause of fracture, after accidental droppings [22]. This finding is reinforced by our study that shows that for complete acrylic dentures perfectly adapted to the supporting tissues the fracture force had an average value of $1722.4 \mathrm{~N}$, well above the maximum value of the masticatory force reported by the studies even in dentulous patients. In our experiment, the force was applied bilaterally, according to Navik's bilateral balanced occlusion concept from 2009, as a way to reduce the probability of complete denture's fracture [21].

Another way to increase complete denture resistance, recommended by various authors, is a metal mesh reinforcement [20]. The metal used as reinforcing material increases the PMMA base resistance [23]. The study conducted by Murthi in 2015 reveals a significant increase in the impact resistance of the stainless-steel mesh reinforced acrylate compared to the unreinforced acrylate [24]. The same result is also obtained by Im et al. in 2017. Furthermore, this study shows that metal reinforcement of denture acrylate provides a superior fracture resistance to that obtained by reinforcement with other materials such as fiberglass [25]. In 2017, Jadhav et al. recommended the reinforcement of heat-processed PMMA, used in manufacturing of maxillary complete dentures in patients with high-arch palate, with laboratory casted stainless-steel mesh in order to increase fracture resistance. The study shows that, although there are no significant differences, a dimension of $4 \times 4 \mathrm{~mm}$ metal mesh gives higher fracture resistance, compared to lower dimensions [26]. Also, our study reveals that by reinforcing the heat-processed acrylate with casted metal mesh, the denture becomes more resistant to forces, the average fracture force value being in this case $3559 \mathrm{~N}$, which is twice the value observed for the fracture of non-reinforced dentures. In 2012, Takahashi et al. showed that the long-term water immersion of complete acrylic maxillary dentures does not 
significantly alter their flexural strength [27]. However, Galev, in 2017, demonstrates in his study that the heat-processed acrylic material used for manufacturing of complete dentures suffers a decrease in flexural strength after 7 days of immersion in water, both for the unreinforced acrylate and the reinforced one [28]. Although in our study the complete dentures were kept in the oral cavity environment for a long period of time (5 years), the heat-processed acrylic material from which they have been made demonstrates a sufficiently high strength, the forces required for fracture greatly exceeding the forces usually developed during mastication.

Previous studies showed that most frequent fracture area of the upper complete denture made of heat-processed PMMA is the median line (59-60\% of all fractures), followed by the incision area [19-20]. In order to prevent fractures, Naik recommends to ensure a sufficient thickness of the acrylic base and in the incisal notch areas [21]. The study conducted by Im et al., in 2017, showed that, most commonly, dentures that are reinforced with metal meshes present fractures of the posterior edge, while the unreinforced dentures present multiple fracture lines, breaking into multiple pieces [25]; this matches the results of our study concerning the classical acrylic complete dentures group, while in the reinforced complete dentures group the fractures were located in the whole periphery of the base and the acrylic teeth.

\section{Conclusions}

Within the limits of our study, we can conclude that heat-processed acrylate ensures a good resistance to fracture for maxillary complete dentures, even after a 5-years period of use, time frame during which its qualities are influenced by specific factors from the oral environment and also by accumulated functional stresses. The resulted necessary forces needed to fracture the heat-processed acrylic base of the maxillary complete dentures proved to be much higher than masticatory forces registered in a dentulous healthy patient. Reinforcement of these denture bases with laboratory metalcasted nets greatly increases their fracture resistance. Therefore, it is improbable that these bases fracture because of the low resistance of the acrylic material to the masticatory forces exerted during function, even in fatigue conditions created by the relative long periods of use (5 years); other factors are more likely to be the cause. In the case of maxillary classic complete dentures group with bases made from heat-processed acrylate, the fracture lines were more than two, the bases broke into multiple pieces involving in most cases fractures on the acrylic teeth. In the case of maxillary reinforced complete dentures group with bases made from heat-processed acrylate reinforced with metal-cast net, the fracture lines were one or two, the bases broke mostly without detachable pieces involving mostly the peripheral area and also involving in most cases fractures on the acrylic teeth.

\section{References}

1. CARLSSON GE, OMAR R. The future of complete dentures in oral rehabilitation. A critical review. J Oral Rehabil. 2010; 37:143-56.

2. DHIR G, BERZINS DW, DHURU VB, PERIATHAMBY AR, DENTINO A. Physical properties of denture base resin potentially resistant to candida adhesion. J Prosthodont. 2007; 16(6):465-72.

3. MENG T, LATTA MA. Physical properties of four acrylic denture base resin. J Contemp Dent Pract. 2005; 6(4):93-100.

4. OLEIWI JK. Studying the Mechanical Properties of Denture Base Materials Fabricated from Polymer Composite Materials. Al-Khwarizmi Engineering Journal. 2018; 14(3):100-11.

5. JAGGER DC, HARRISON A, JANDT KD. The reinforcement of dentures. J Oral Rehabil. 1999; 26: 185-194.

6. BEYLI MS, VON FRAUNHOFER JA. An analysis of causes of fracture of acrylic resin dentures. J Prosthet Dent. 1981; 46: $238-241$.

7. DARBAR UR, HUGGETT R, HARRISON A. Denture fracture-a survey. Br Dent J. 1994; 176:342-345.

8. CHAND P, PATEL CBS, SINGH BP, SINGH RD, SINGH K. Mechanical properties of denture base resins: An evaluation. Indian J Dent Res. 2011; 22(1): 180.

9. NEJATIAN T, JOHNSON A, VAN NOORT R. Reinforcement of denture base resin. Adv Sci Tech. 2006; 49:124-29.

10. GAD MM, AL HARBI FA, NÄPÄNKANGAS R, RUSTIA A. PMMA denture base material enhancement: a review of fiber, filler, and nanofiller addition, Int J Nanomedicine 2017; 12: 3801- 12.

11. ALHAREB AO, AKIL H M, AHMAD ZA. Impact strength, fracture toughness and hardness improvement of PMMA denture base through addition of nitrile rubber/ceramic fillers. Saudi J Oral Dent Res. 2017; 8 (1-2):26-34.

12. TOMOYUKI I, HAJIME S, NORYUKI W, TAKASHI O. Effect of cross section shape of metal strengthener on stress distribution in acrylic denture bases. Prosthodont Res Pract. 2004; 3:1-7.

13. STEINMASSL O, OFFERMANNS V, STÖCKL W, DUMFAHRT H, GRUNERT I, STEINMASSL PA. In Vitro Analysis of the Fracture Resistance of CAD/CAM Denture Base Resins. Materials (Basel) 2018; 11(3):401.

14. RAY BHATTACHARYA S, RAY PK, MAKHAL M, SEN KS. Incidence and causes of fracture of acrylic resin complete denture. J Evolution Med Dent Sci. 2014; 69(3):14787-93.

15. BORȚUN C, FAUR N, MARSAVINA L, CERNESCU A, GOMBOS O, SZABO L. Durability experimental tests for a Superacryl Plus complete denture. Timișoara Med J. 2010; 60(4):269-73.

16. OKAMOTO H, ASANO T. Comparative Study of Bite Force in Healthy Dentate Individuals and Complete Denture Wearers, Int J Oral-Med Sci. 2012;10(4):400-5.

17. FAYAD MI, ALRUWAILI HHT, KHAN MS, BAIG MN. Bite Force Evaluation in Complete Denture Wearer with Different Base Materials: A Randomized Controlled Clinical Trial. J Int Soc Prev Community Dent. 2018; 8(5):416-19.

18. SHALA K, TMAVA-DRAGUSHA A, DULA L, PUSTINA-KRASNIQI T, AHMEDI E, LILA Z. Evaluation of Maximum Bite Force in patient with Complete Dentures. Open Acces Maced J Med Sci. 2018; 6(3):559-63. 
19. BOSÂNCEANU N, BELDIMAN A, BACIU RE, BOLAT M, BOSÂNCEANU DG, FORNA NC. Complete dentures fractures - causes and incidence. J Oral Rehabilit. 2017; 9(1):54-9.

20. ZANCO HK. Causes and types of complete denture fracture. J Med Sci. 2011; 15(3):36-40.

21. NAIK AV. Complete denture fractures: A clinical study. J Indian Proshodont Soc. 2009; 9:148-50.

22. SHAKIR S, JALIL H, KHAN MA, QAYUM B, QADEER A. Causes and Types of Denture Fracture - A Study. Pak Oral Dent J. 2017; 37(4): 634-37.

23. VALLITTU PK, LASSILA VP. Reinforcement of acrylic denture base material with metal or fibre strengtheners. J Oral Rehabil. 1992; 19(3):22530 .

24. MURTHHY HBM, SHAIK S, SACHDEVA H, KHARE S, HARALUR SB, ROOPA KT. Effect of Reinforcement Using Stainless Steel Mesh, Glass Fibers, and Polyethylene on the Impact Strength of Heat Cure Denture Base Resin - An In Vitro Study. J Int Oral Health. 2015; 7(6):71-9.

25. IM SM, HUH YH, CHO LR, PARK CJ. Comparison of the fracture resistance of glass fiber mesh- and metal mesh-reinforced maxillary complete denture under dynamic fatigue loading. J Adv Prosthodont. 2017; 9(1):22-30.

26. JADHAV SS, SANYAL PK, TEWARY S, GURU R, JOSHI S, KORE A. Comparison of Mechanical Strength of Palatal Denture Base using Four Mesh Designs on Shallow Palatal Vault Configuration: An in vitro Study. Int J Prev Clin Dent Res. 2017; 4(3):1-9.

27. TAKAHASHI Y, YOSHIDA K, SHIMIZU H. Fracture resistance of maxillary complete dentures subjected tolong-term water immersion. Gerodontology. 2012; 29:e1086-e1091.

28. GALAV A, DEOGADE SC, MANTRI S, SUMATHI K, GALAV S. Effect of water storage on the flexural strength of heat-cured denture base resin reinforced with stick (s) glass fibers. Contemp Clin Dent. 2017; 8(2):264-71.

Manuscript received: 17. 10. 2019 
